\section{Aporoted for public release;} distribution is unlimited.
Title:

Author(s):

Submitted to:
SINGLE-PHASE AC LOSSES IN PROTOTYPE HTS CONDUCTORS FOR

SUPERCONDUCTING POWER TRANSMISSION LINES

$$
\text { CONF-980569-- }
$$

David E. Daney, Martin P. Maley, Heinrich J. Boenig, Jeffrey O.Willis, J. Yates Coulter

Int' 1 Cryogenic Materials Conf./Ac Loss and Stability Enschede, The Netherlands

$5 / 10-13 / 98$
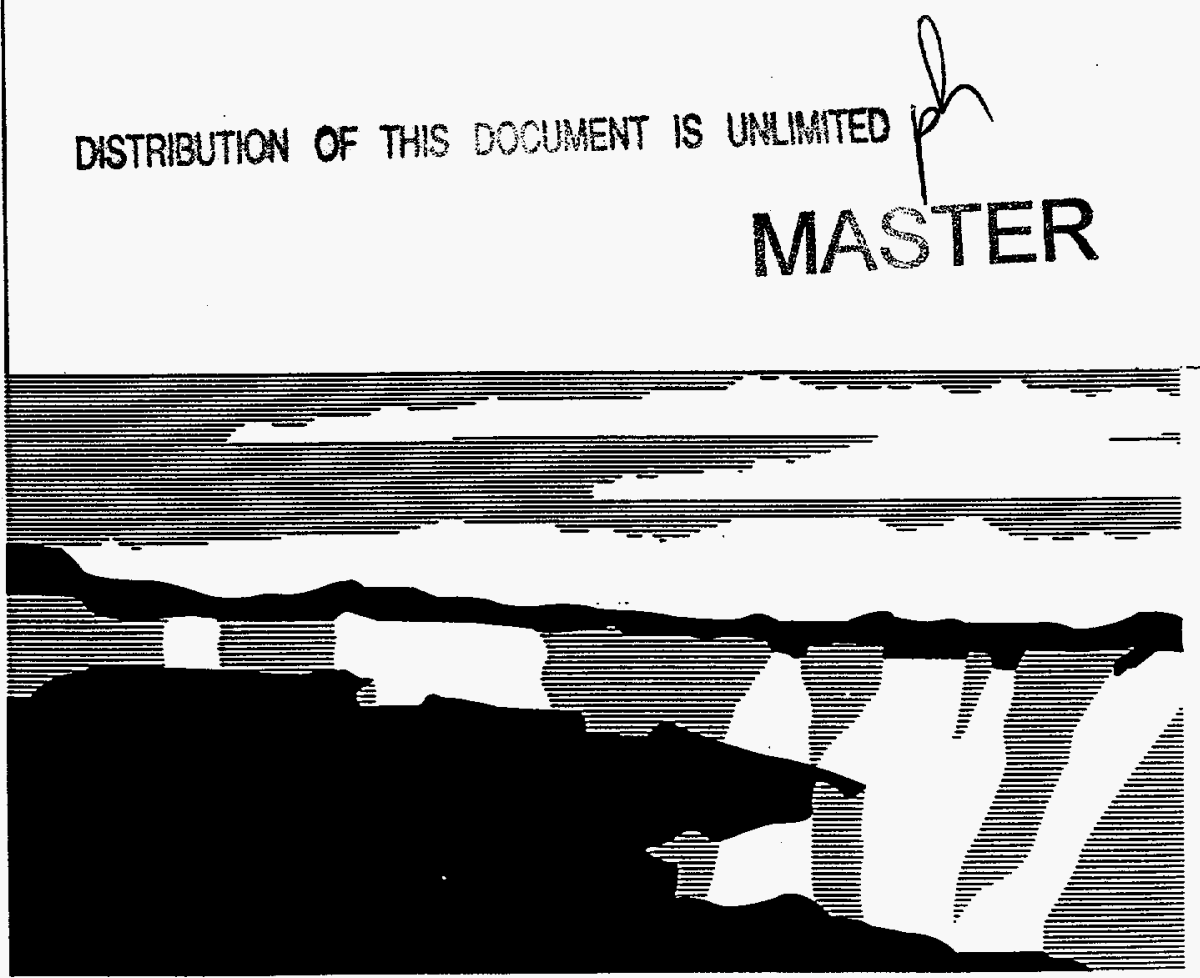

Los Alamos National Laboratory, an affirmative action'equal opportunity employer, is operated by the University of Califomia for the U.S. Department of Energy under contract W-7405-ENG-36. By acceptance of this article, the publisher recognizes that the U.S. Govermment retains a nonexclustve, royalty-free license to publish or reproduce the published form of this contribution, $\alpha$ to allow others to do so, for U.S. Govermment purposes. Los Alamos National Laboratory requests that the publisher identify this article as work performed under the auspices of the U.S. Department of Energy. The Los Alamos National Laboratory strongly supports academic freedom and a researcher's right to publish; as an institution, however, the Laboratory does not endorse the vieupoint of a publication or guaranteo its technical correctness. 


\section{DISCLAIMER}

This report was prepared as an account of work sponsored by an agency of the United States Government. Neither the United States Government nor any agency thereof, nor any of their employees, makes any warranty, express or implied, or assumes any legal liability or responsibility for the accuracy, completeness, or usefulness of any information, apparatus, product, or process disclosed, or represents that its use would not infringe privately owned rights. Reference herein to any specific commercial product, process, or service by trade name, trademark, manufacturer, or otherwise does not necessarily constitute or imply its endorsement, recommendation, or favoring by the United States Government or any agency thereof. The views and opinions of authors expressed herein do not necessarily state or reflect those of the United States Government or any agency thereof. 


\section{DISCLAIMER}

Portions of this document may be illegible in electronic image products. Images are produced from the best available original document. 


\title{
Single-phase ac losses in prototype HTS conductors for superconducting power transmission lines
}

\author{
D. E. Daney, M. P. Maley, H. J. Boenig, J. O. Willis, J. Y. Coulter \\ Los Alamos National Laboratory, USA \\ L. Gherardi, G. Coletta \\ Pirelli Cavi SpA, Italy
}

\begin{abstract}
We report single-phase ac loss measurements on 8, 4, and 3-layer, multi-strand, HTS prototype conductors for power transmission lines. We use both calorimetric and electrical techniques. The agreement between the two techniques suggests that the interlayer current distribution in one-meter long conductors are representative of those in long conductors. The losses for the 8 and 4-layer conductors are in rough agreement, with the 8-layer losses being somewhat lower. The 3-layer conductor losses are substantially higher -- probably due to unbalanced azimuthal currents for this configuration.
\end{abstract}

\section{Introduction}

We are studying ac losses in prototype HTS superconducting power transmission lines (SPTLs) as a first phase in the development of an HTS "pipe" type conductor for retrofit upgrading the capacity of an existing $115 \mathrm{kV}$ transmission line from 220 to 400 MVA. The effort is a part of a U.S. DOE Superconductivity Partnership Initiative (SPI) program. As a step in understanding ac losses in multilayer HTS-SPTLs, we measured single and three-phase losses in 8,4 and 3-layer multi-strand conductors. It has previously been demonstrated by Mukoyama et al.[1] that forcing equal distribution of current amongst the layers of a multilayer conductor results in substantial reductions of ac losses compared with the usual Bean-critical-state distribution where most of the current flows in the outer layers at low ac current levels. Clem [2] has shown that multilayer-conductor current distributions, driven predominantly by self- and mutual inductance, are modifications of the non-uniform "Bean" distribution with concentration in the outer layers, but with some current flowing in the inner layers even at low total current. This results in some small reductions in ac loss from the Bean solid conductor case, but in losses that are substantially greater than in the even distribution case. In short conductor measurements resistive losses at the conductor end connectors may force a different distribution in currents than would be the case in a long conductor where inductance dominates. By comparing losses in conductors containing different numbers of layers, we will obtain evidence concerning the current distribution. In this paper we report on our single-phase loss measurements, especially in regard to comparison and equivalence between diverse measurement techniques.

The 8-layer conductor is a segment from a conductor machine-wound at Pirelli. Its layers are helically wound, the alternate layers wrapped with alternating pitch so that the net azimuthal component of current in the conductor is nearly zero. We use a one-meter long sample for the calorimetric measurements and a 13-meter long sample for the electrical 
measurements. The 4 and 3layer conductors (calorimetric measurements only) were created by peeling off successive layers of the original 8-layer conductor. The 3-layer conductor tests the effect of an uneven number of layers with a resulting axial magnetic field.

\section{Experimental}

Both calorimetric and electrical techniques are used for the ac loss measurements. Los Alamos made the calorimetric measurements, and Pirelli made the electrical ones. The ac current frequency is $60 \mathrm{~Hz}$ for all results reported here.

Calorimetric measurements are based on a temperature difference technique in which the circumferential perimeter of the conductor is vacuum insulated, so that the conductor sample is cooled only at its ends. The conductor then develops a parabolic temperature distribution when carrying ac current, and the ac loss per unit length, $\mathrm{q}_{\mathrm{L}}$, obtained from the steady-state conduction equation is

$$
\mathrm{q}_{\mathrm{L}}=\frac{8 \mathrm{kA} \Delta \mathrm{T}_{\mathrm{m}}}{\mathrm{L}^{2}}
$$

where $\mathrm{k}$ is the effective thermal conductivity of the conductor, $\mathrm{A}$ is the conductor crosssectional area, $\mathrm{L}$ is the conductor length, and $\Delta \mathrm{T}_{\mathrm{m}}$ is the difference between the temperature at the center of the conductor and the average of the two end temperatures. In situ calibration with a heater wound at the axial midpoint of the conductor gives the effective $\mathrm{kA}$, and $\Delta \mathrm{T}_{\mathrm{m}}$ is determined from a curve fit to the temperatures registered by 14 platinum resistance thermometers positioned axially and azimuthally on the conductor.

The calorimeter [3] has three phases ( a superconducting phase and two normal phases) arranged in an isosceles triangle, allowing both single and three-phase measurements. The sensitivity of the calorimeter is better than $1 \mathrm{~mW} / \mathrm{m}$ and the systematic error is about 5 percent. The liquid nitrogen bath pressure can be controlled to give conductor temperatures between 64 and $78 \mathrm{~K}$. The conductor is powered by a variable ac, $60 \mathrm{~Hz}$, three-phase current source with continuously adjustable current from zero to 2500 A rms.

As mentioned, ac losses are also measured by an electrical "transport" method which singles out the component of the conductor voltage drop in phase with the transport current by means of a lock-in amplifier. To achieve this result a reference signal with known phase with respect to the conductor current is necessary. For this purpose we have developed a perfectly inductive, Rogowsky-like coil suitable for providing a signal shifted 90 degrees with respect to the current. With this device it is also possible to derive a finely variable signal used to compensate the inductive component of ac voltage, which in conductors (as well as in tapes) far exceeds the resistive component. To supply a sufficiently stable and harmonic-free current signal of the order of $2000 \mathrm{~A}$, and variable in frequency in the range around the mains frequency of $50 \mathrm{~Hz}$, we have developed a power supply system energized by up to three power amplifiers ( $3 \mathrm{~kW}$ each), operating in series. In order to reach the maximum possible current amplitude in actual conditions, where the inductive component of the "load" far exceeds the resistive one, it is necessary to couple the amplifier outputs to resonant circuits, which also improve the quality of the signal at the selected frequency. 
To minimize the influence of the magnetic field produced by the return current on both the conductor sample and the environment, the return copper conductor was split into two branches, symmetrically placed in the same plane as that of the sample.

\section{Experimental Results and Discussion}

One question regarding the use of meter-long conductors in the Los Alamos calorimeter is whether or not the losses are the same as for long conductors because of possible differences in the inter-layer current distribution. Figure 1, which compares the electrical and calorimetric single-phase ac loss measurements for the 8-layer conductor, shows good agreement between the Los Alamos one-meter conductor calorimetric measurements and the Pirelli 13-meter conductor electrical measurements. The consistency of these two very different techniques supports the validity of the results and suggests that the current distributions in the short and long conductors are similar. A more even distribution between layers driven by resistive end connections would have resulted in substantially reduced losses in the $1-\mathrm{m}$ conductor. This result suggests that it is possible to realize suitable end connections such that even at one meter the current distributions are determined by inductive effects. Consequently, the one-meter results can be taken as representative of losses in a long conductor.

Figures 2 and 3 show the dependence of the ac loss on current with the number of layers as a parameter for temperatures of $76 \mathrm{~K}$ and $70 \mathrm{~K}$, respectively. For both temperatures there is a rough agreement of the losses for the 4 and 8-layer conductors with the 8-layer losses lying somewhat lower. This is in general agreement with expectations for inductance determined current distribution where most of the current is carried by the outer layers and the losses are insensitive to the number of layers at currents below the critical current for the 4-layer conductor. For the $76 \mathrm{~K}$ measurements the exponents of curve fits to the mid-range currents are about 2.8 for the 3-layer conductor, and 3.1 for the 4 and 8layer conductors. For the $70 \mathrm{~K}$ measurements the exponent is about 2.6. A detailed analysis of the effect of temperature, taking into account also the temperature-dependence of possible non-hysteretic mechanisms, has not been carried out yet, but will be addressed in the near future.

The 3-layer conductor losses are substantially higher and probably indicate the effect of unbalanced azimuthal currents in the conductor. This is illustrated in Fig. 4, where we show the axial magnetic field versus current measured by a calibrated pickup coil for the 3 and 4-layer conductors. It is clear that the axial field is roughly an order of magnitude higher for the 3-layer conductor at the high current levels. For an even number of counterwound layers inductive coupling will tend to drive equal currents through alternate layers resulting in near cancelation of the axial field. For the uneven layer number case the uncanceled axial ac magnetic field will generate an azimuthal emf that will drive eddy currents in all of the layers. This is the likely origin of the enhanced losses, as well as of the lower slope of the loss curve.

\section{Summary}

We have measured ac losses by both electrical and calorimetric techniques on multilayer transmission conductors wound from $\mathrm{Bi}-2223$ multifilamentary tapes. The electrical and calorimetric losses are in good agreement, and the comparison between 1-m and 13-m lengths indicates that both are in agreement with a critical state model in which inductance drives most of the current in the outer layers at currents below the critical current of the conductors. This conclusion is further corroborated by comparison of ac losses between 4 
and 8- layer conductors, which agree closely, in contrast to the expectations for a more even distribution of current amongst the layers, which would have led to substantially reduced losses for the 8-layer conductor. Measurement of ac losses in an unbalanced 3layer conductor show large enhancement of the losses coming from an uncompensated axial field which drives azimuthal currents in the conductor.

\section{References}

[1] S. Mukoyama, K. Miyoshi, H. Tsubouti, M. Mimura, N. Uno, N. Ichiyanagi, Y. Tanaka, M. Ikeda, H. Ishii, S. Honjo, Y. Sato, T. Hara and Y. Iwata, IEEE Trans.On Appl._Supercon. 7 (1997) 1069

[2] J. Clem-private communication

[3] D. E. Daney, H. J. Boenig, M. P. Maley, J. Y. Coulter and S. Fleshler, Adv. Cryogenic Eng. - Materials 44 (1998) 


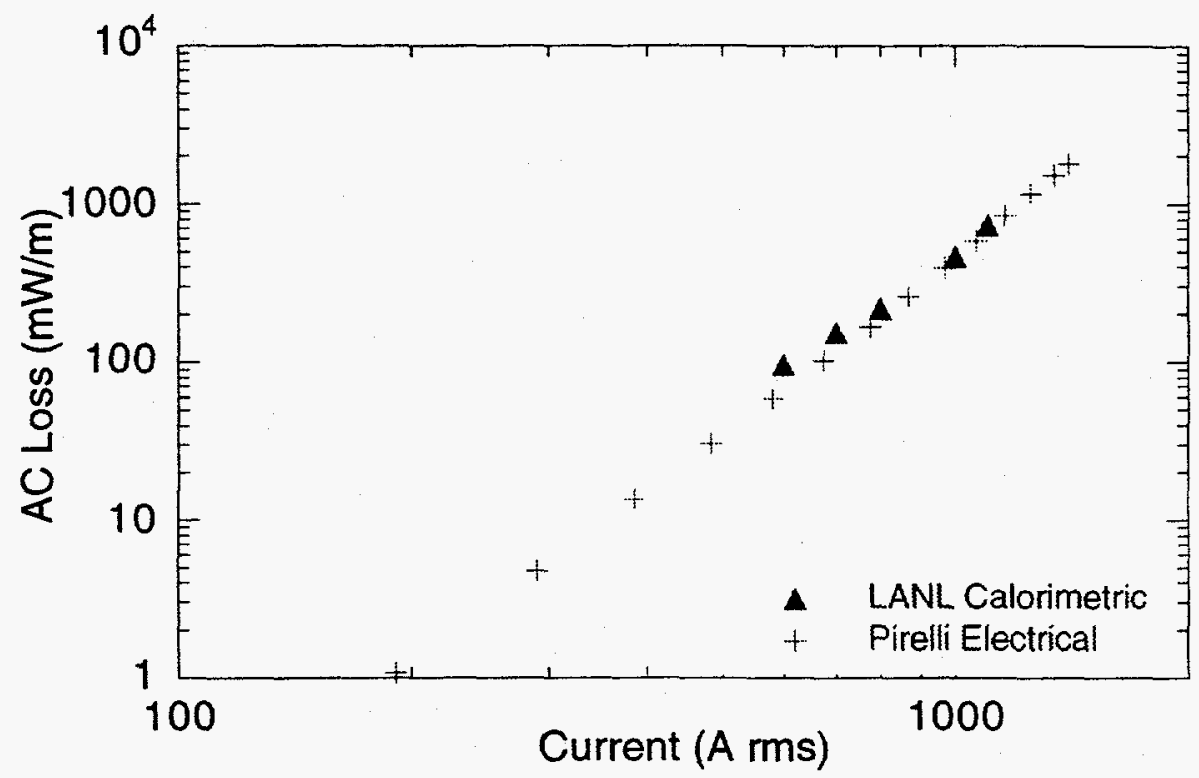

Fig. 1. Comparison of calorimetric and electrical ac loss measurements on the Pirelli 8 - layer conductor.

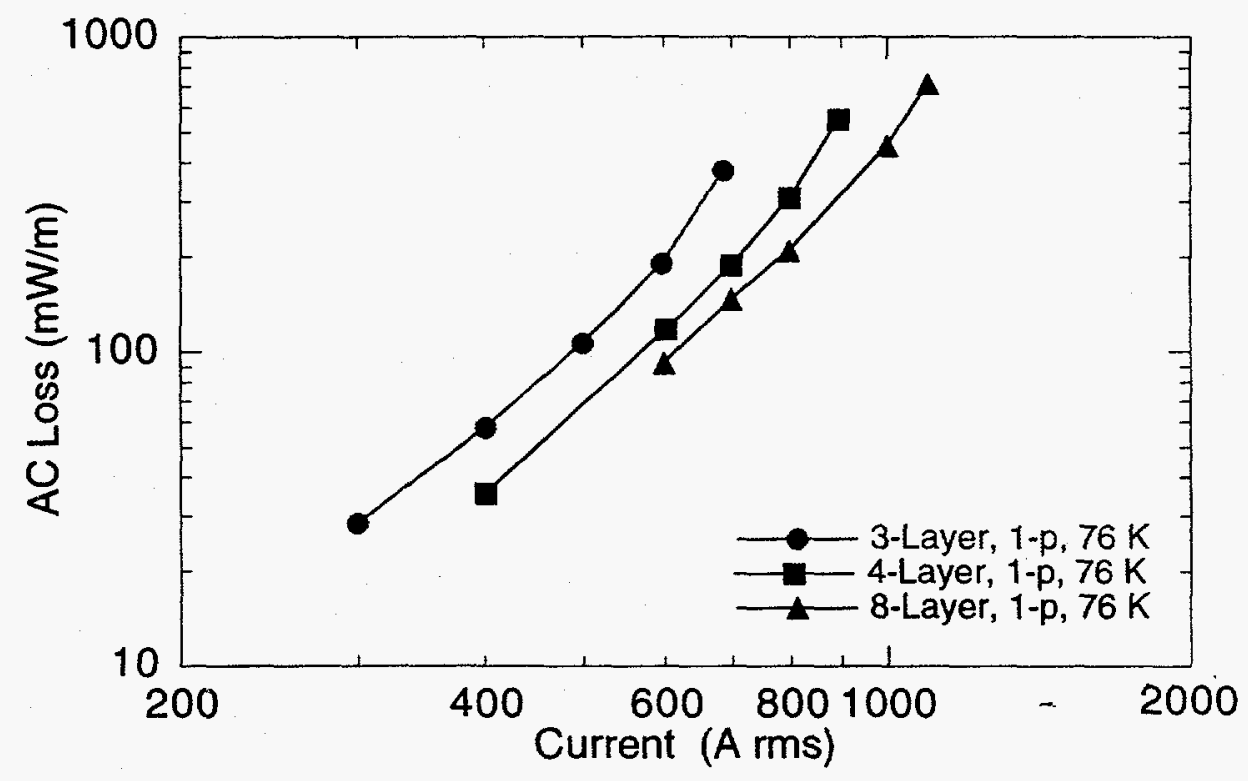

Fig. 2. Calorimetric ac loss measurements on the Pirelli 8, 4, and 3-layer conductors at $76 \mathrm{~K}$. 


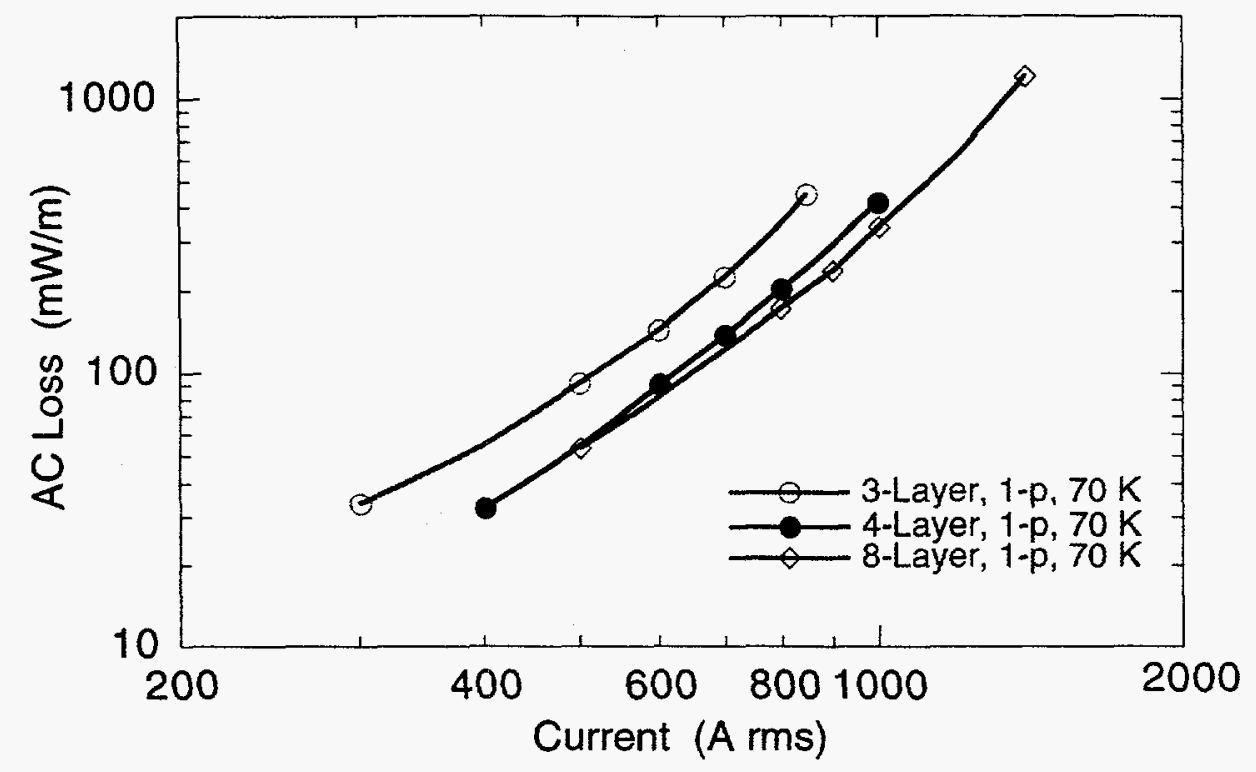

Fig. 3. Calorimetric ac loss measurements on the Pirelli 8, 4, and 3-layer conductors at $70 \mathrm{~K}$.

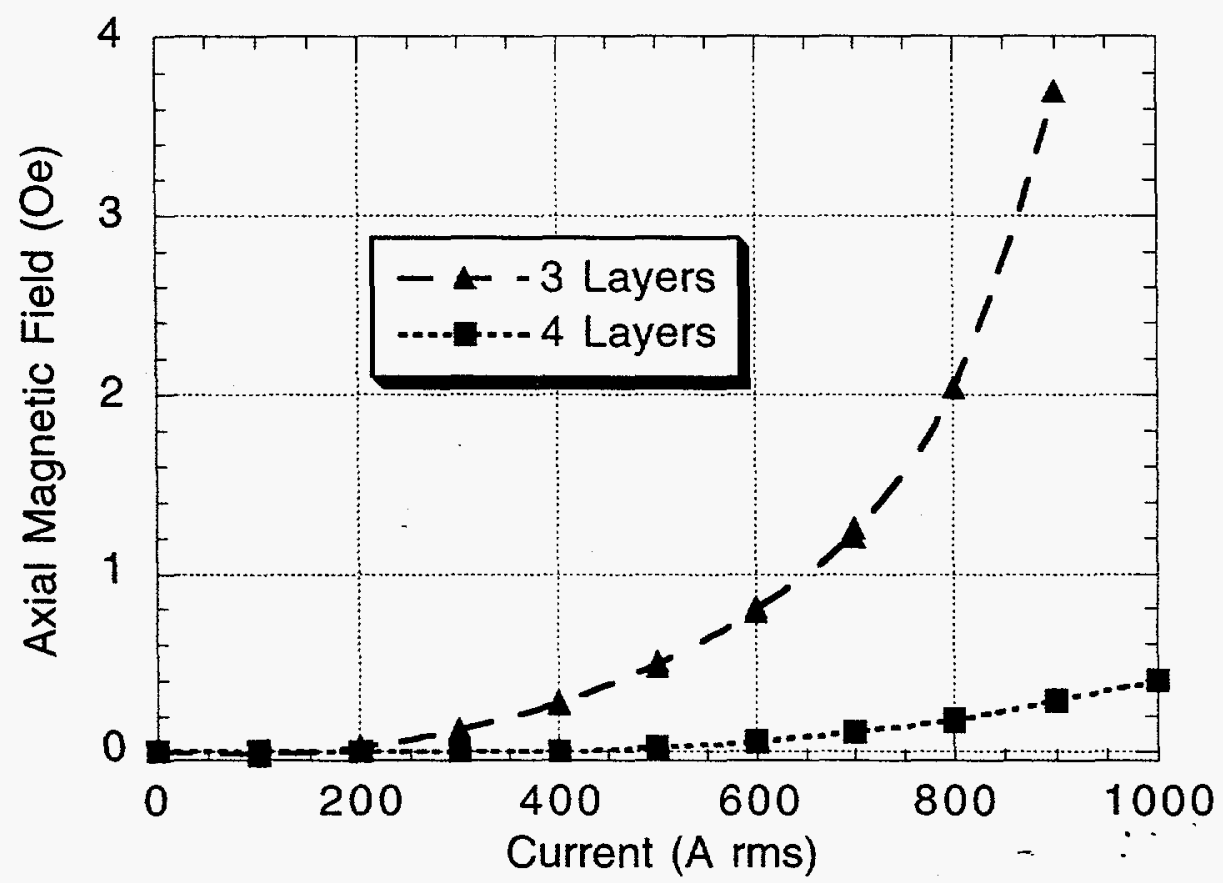

Fig. 4. Comparison of the axial field inside the 3 and 4-layer conductors at the axial midpoint. The conductor temperature is $75.3 \mathrm{~K}$. One Oe is equivalent to a current imbalance of $25 \mathrm{~A}$. 